\title{
Protective effect of glutathione on Escherichia coli cells upon lethal heat stress
}

\author{
María Marcén, Guillermo Cebrián, Virginia Ruiz-Artiga, Santiago Condón, Pilar Mañas* \\ Tecnología de los Alimentos, Facultad de Veterinaria de Zaragoza, Instituto Agroalimentario de Aragón- IA2, Universidad de Zaragoza-CITA, Zaragoza, Spain
}

\section{A R T I C L E I N F O}

\section{Keywords:}

Escherichia coli

Glutathione

Heat treatment

ROS

Membrane

Protein

Sublethal damage

\begin{abstract}
A B S T R A C T
Heat treatments are widely used by the food industry to obtain safe and stable products, therefore a deeper knowledge of its mode of action on microorganisms would allow a better profit of this technology. Heat shows a multitarget mechanism of action on bacteria, affecting various cellular structures, and causing unbalances in several homeostatic parameters. The aim of this work was to study the effect of glutathione on bacterial survival against heat treatments, in order to acquire knowledge about the mode of action of heat on bacterial cells. Cells were treated in presence or absence of added glutathione and the level of inactivation, soluble protein concentration, enzymatic activities, intracellular ROS level and membrane damages were studied. Results showed that glutathione protected microorganisms against heat inactivation. Moreover, glutathione in the treatment medium preserved intracellular enzyme activity, membrane structure and reduced ROS detection. Besides, glutathione decreased sublethal injury in $E$. coli. Data presented in this work add new knowledge about bacterial inactivation and survival by heat.
\end{abstract}

\section{Introduction}

Heat treatments are commonly used by the food industry to inactivate pathogenic and spoilage microorganisms. Despite the wide use of thermal treatments, many aspects about its mode of action on microorganisms still remain unclear. A better knowledge of the physiology of microbial inactivation by heat would permit to obtain a better profit of this technology (Smelt \& Brul, 2014). Heat shows a multitarget mode of action in bacteria, causing damages in different cell structures such as the envelopes, DNA, RNA, ribosomes and particular enzymes (Cebrián, Condón, \& Mañas, 2017; Mackey, 2000; Nguyen, Corry, \& Miles, 2006). Such cellular damages, depending on their intensity and severity, may cause cell inactivation and/or the occurrence of sublethally injured cells. These can be defined as cells able to grow and survive only under appropriate environmental conditions that allow the recovery of the cellular lesions before growth is resumed (Mackey, 2000). The final events leading to lethal or sublethal injury in bacterial cells, and the physiology of cell recovery have not been sufficiently studied, despite their practical importance for the food industry.

One of the physiological aspects that is gaining attention in the last years is the involvement of an oxidative component in the inactivation and damage of cells exposed to a variety of agents used in the food industry, such as heat, acid or high hydrostatic pressure (Aertsen, De
Spiegeleer, Vanoirbeek, Lavilla, \& Michiels, 2005; Marcén, Ruiz, Serrano, Condón, \& Mañas, 2017; Mols, Van Kranenburg, Van Melis, Moezelaar, \& Abee, 2010). It has been suggested that exposure to agents of several nature may cause an unbalance in the intracellular redox homeostasis (Mols \& Abee, 2011) that could contribute to cell inactivation and sublethal injury. The causes behind an impaired cellular redox homeostasis after exposure to a stressing agent include, among other mechanisms, an increase in the generation of reactive oxygen species, disulfide bond formation in proteins, disassembly of iron-sulfur clusters, and denaturation of protective enzymes (catalases, alkylhydroperoxidases, superoxide dismutases, enzymes of the thioredoxin and glutathione systems)(Cabiscol, Tamarit, \& Ros, 2000; Imlay, 2013).

Glutathione is considered as the most potent natural antioxidant molecule, with important cellular functions in eukaryotic cells; however its role in prokaryotes has received less attention (Smirnova \& Oktyabrsky, 2005). Glutathione is present only in some bacterial genera, mostly Gram negative (Fahey, Brown, Adams, \& Worsham, 1978), although analogs have been described in other bacterial groups (Fahey, 2013). It is a tripeptide (L- $\gamma$-glutamyl-L-cysteinyl-glycine) with reducing properties and ability to eliminate free radicals, due to the presence of a sulfhydryl group in the cysteine, which can serve as an electron donor. Glutathione (GSH) reacts with free radicals, and participates in thiol-disulfide interchanges with proteins and other thiols,

\footnotetext{
* Corresponding author at: Tecnología de los Alimentos, Facultad de Veterinaria, C/ Miguel Servet, 177, 50013 Zaragoza, Spain.

E-mail address: manas@unizar.es (P. Mañas).
} 
rendering mixed disulfides and glutathione disulfide dimers (GSSG). GSSG is then recycled through the action of the enzyme glutathione reductase (gor), and mixed disufildes are also recycled by the action of glutaredoxins (grx) (Smirnova \& Oktyabrsky, 2005). It has been suggested that glutathione could exert an important role in stress resistance in bacteria, however little information is available on stresses other than direct oxidative agents. To this regard, it has been demonstrated that $E$. coli mutant strains defective in glutathione synthesis or in glutathione reductase activity are less resistant to osmotic stress and to acid pH (Masip, Veeravalli, \& Georgiou, 2006; Smirnova \& Oktyabrsky, 2005).

In a previous work carried out in our laboratory, we observed that the addition of glutathione to the heating medium protected $E$. coli against inactivation (Marcén et al., 2017). The objective of this work was to further study the effect of glutathione on bacterial survival to heat, using $E$. coli as a model microorganism, with the final aim of gaining insight into the physiological mechanism of cell protection, and obtaining a deeper knowledge about the mode of action of heat on bacterial cells.

\section{Material and methods}

\subsection{Bacterial strains and growth conditions}

Escherichia coli BW25113, E. coli CECT 4201, Salmonella enterica serovar Senftenberg $775 \mathrm{~W}$ and Lactobacillus plantarum CECT 748 were used in this study. The strains were stored at $-80^{\circ} \mathrm{C}$. To prepare precultures, flasks containing $10 \mathrm{ml}$ of sterile broth were inoculated with one single colony from an agar plate. The precultures were incubated overnight at $37^{\circ} \mathrm{C}$, under agitation. Subsequently, cultures were obtained by inoculating a flask with $50 \mathrm{ml}$ of broth with $100 \mu \mathrm{l}$ of the preculture, and incubation at $37^{\circ} \mathrm{C}$ under agitation, until stationary phase of growth was reached after 18-24 h incubation $\left(2 \times 10^{9} \mathrm{cfu} / \mathrm{ml}\right.$, approximately). Media used were TSBYE and TSAYE (Tryptic Soy Broth or Agar, respectively, with 0.6\% Yeast Extract, Oxoid, Basingstoke, UK) for E. coli and Salmonella, or MRS broth and agar (Oxoid) for L. plantarum. Unless otherwise indicated, E. coli and Salmonella were grown under aerobic atmosphere, whereas L. plantarum was grown under anaerobic atmosphere in a variable atmosphere incubator (MACS VA500, Don Whitley Scientific Limited, Shipley, United Kingdom), with a gas composition of $0 \%$ oxygen, $5 \%$ hydrogen, $5 \%$ carbon dioxide and $90 \%$ nitrogen, plus the palladium catalyzer.

In some experiments, where specified in the text, $10 \mathrm{mM}$ of filtersterilized reduced L-glutathione (Sigma-Aldrich) was added to the growth medium. This concentration, chosen in preliminary experiments, did not inhibit the growth of $E$. coli untreated cells neither in liquid nor in solid media (data not shown).

\subsection{Heat treatments}

To determine the heat resistance of $E$. coli, heat treatments were carried out in glass tubes, which contained $4.5 \mathrm{ml}$ of sterile PBS (Phosphate Buffered Saline, Sigma, San Louis, USA), submerged in a thermostated water bath. Once the PBS reached the desired temperature $\left(58^{\circ} \mathrm{C}\right)$, it was inoculated with $0.5 \mathrm{ml}$ of the microbial cell suspension to obtain a concentration $\geq 10^{8}$ cells $/ \mathrm{ml}$. After inoculation, $0.1 \mathrm{ml}$ samples were collected at different heating times $(1,5$ and $10 \mathrm{~min}$ for $E$. coli, $20 \mathrm{~min}$ for $S$. enterica, and $6 \mathrm{~min}$ for L. plantarum) for survival counting. Conditions of heat treatment (time/temperature) for each microorganism were determined in preliminary experiments and were chosen in order to reach an inactivation level of 2-3 Log cycles (data not shown). When needed, reduced glutathione was added to the sterile PBS at the desired concentration $(10 \mathrm{mM}$ for E. coli and $S$. enterica, and $5 \mathrm{mM}$ for L. plantarum). The concentration of glutathione was chosen from preliminary experiments with $E$. coli as the maximum that did not sensitize cells against heat treatments (data not shown).

\subsection{Recovery in agar after heat treatment}

After heat treatment in PBS with or without glutathione, samples were serially diluted, plated in TSAYE, and incubated at $37^{\circ} \mathrm{C}$ in aerobic conditions, for E. coli and Salmonella enterica. For L. plantarum, MRS-agar and anaerobic conditions were used. After 24-48 h, colony forming units were counted. Plates were counted after incubation, and results were expressed as the number of Log cycles of inactivation after a fixed treatment time.

Although these were the standard recovery conditions used in most experiments, in experiments carried out to study the occurrence and repair of sublethal injury, cells were also recovered under different conditions, as explained in next section.

\subsection{Study of sublethal injury repair in liquid medium after heat treatment}

To study the different phenomena during recovery, E. coli cells were heat treated at $58^{\circ} \mathrm{C}$ for 1 in PBS with or without glutathione $(10 \mathrm{mM})$ added, and then suspended in TSBYE and in TSBYE plus $10 \mathrm{mM}$ glutathione added ( $10 \mathrm{ml}$ of total volume), at $37^{\circ} \mathrm{C}$. Samples were collected after different times (0-120 min) and plated in the non-selective and in the selective agars. Selective agars were TSAYE with $\mathrm{NaCl}$ (4.0\%, Panreac) or bile salts added (0.2\%, Oxoid) (TSAYE-NaCl, TSAYE-BS). These concentrations correspond to the maximum non inhibitory concentrations for native cells, and were previously determined (data not shown). It is generally assumed that the presence of $\mathrm{NaCl}$ prevents the outgrowth of cells with a damaged cytoplasmic membrane, whereas the presence of bile salt prevents the outgrowth of cells with a damaged outer membrane (Mackey, 2000). On the other hand, as non selective agars, we used TSAYE and MM-Cys. MM-cys consists of minimal medium M9 glucose-salts agar supplemented with $\mathrm{FeSO}_{4}(10 \mathrm{mg} / \mathrm{L})$ (Gerhardt, 1994; Stanier \& Villanueva, 1996), and enriched with $3 \mathrm{mML}$-cysteine $\mathrm{HCl}$ to create a low redox potential environment (Gerhardt, 1994; Suh \& Knabel, 2000). This agar was chosen to improve the recovery of cells (Marcén et al., 2017). In this latter case, anaerobic atmosphere was used in order to further reduce the oxidative component of the recovery conditions, and $72 \mathrm{~h}$ were allowed for full colony development.

These plates were counted after incubation, and results were expressed as the number of viable cells per $\mathrm{ml}$ after a fixed treatment and incubation time.

\subsection{Fluorescence staining}

The presence of ROS and the permeabilization of the membrane in cells were studied through staining with specific fluorochromes followed by epifluorescence microscopy (Marcén et al., 2017). Treated cells, at approximately $10^{8}$ cells, were centrifuged $(6708 \mathrm{~g} / 5 \mathrm{~min})$, resuspended in PBS and incubated with the desired fluorescence dye.

To detect the presence of ROS, cells were stained with dihydroethidium (DHE, $50 \mu \mathrm{M} / 90 \mathrm{~min}$ ). DHE is a membrane-permeable probe that binds to DNA upon oxidation by ROS, including superoxide, rendering a strong red fluorescence (Gomes, Fernandes, \& Lima, 2005). To study the permeabilization of the membrane, cells were stained with propidium iodide (PI, $3 \mu \mathrm{M} / 30 \mathrm{~min}$ ). Cells with permeabilized membranes allow the entrance of the dye inside the cell, rendering cells with intense red fluorescence.

A positive and a negative control of staining were always included. The negative control corresponded to untreated cells, whereas the positive control consisted of cells exposed to the superoxide-generating agent plumbagin (Sigma Aldrich) $(5.3 \mathrm{mM} / 10 \mathrm{~min})$ in the case of DHE (Farr, Natvig, \& Kogoma, 1985; Hassan \& Fridovich, 1979), or exposed to an intense heat treatment $\left(70{ }^{\circ} \mathrm{C} / 20 \mathrm{~min}\right)$, in the case of PI. To analyze samples, a Nikon Eclipse $\mathrm{E} 400$ phase contrast and fluorescence microscope (Nikon Corporation, Japan) was used. Images were obtained with a high resolution camera (AxioCam MRc, Zeiss, Germany) 
and processed with the software ZEN 2012 (Zeiss, Germany). Total and fluorescent cells were counted from photographs taken from each sample, and at least three different representative microscopic fields, containing 100-200 cells, approximately, were used for quantification.

To detect and visualize protein aggregates, cells were stained with fluorescein sodium salt (Sigma-Aldrich) (Mañas \& Mackey, 2004), with a final concentration of $65 \mu \mathrm{M}$, for $10 \mathrm{~min}$. After this contact time, cells were washed three times to eliminate the background and observed under epifluorescence microscope.

\subsection{Determination of intracellular glutathione and soluble protein}

The relative intracellular glutathione was determined in $E$. coli cells treated in the presence or absence of glutathione $\left(58^{\circ} \mathrm{C} / 5 \mathrm{~min}\right)$. In all cases, cells were washed three times in PBS by centrifugation $(6708 \mathrm{~g}$ / $5 \mathrm{~min}$ ), concentration was adjusted to $10^{8} \mathrm{cells} / \mathrm{mL}$, and cells were lysed with $0.1 \mathrm{~mm}$ glass beads in a bead-beater instrument (BioSpec product, Oklahoma, USA). Five rounds of $10 \mathrm{~s}$ were applied, and samples were cooled on ice between rounds. It was checked through microscopic examination that $>95 \%$ of cells had been lysed. Lysed samples were centrifuged and the supernatant (soluble fraction) was reserved for analysis of glutathione and protein content. Total glutathione was determined with the Glutathione Assay Kit (SigmaAldrich), based on the determination of sulfhydryl groups (Ellmman's reactive), using the enzyme glutathione reductase plus NADPH to recycle oxidized glutathione. Protein content was determined by the Bicinchoninic Acid (BCA) method following the standard protocol and using bovine serum albumin as standard (Sigma-Aldrich). Results were expressed as $\mathrm{nM}$ of glutathione per $\mathrm{ml}$ and $\mathrm{mg}$ of protein per $\mathrm{ml}$ of cell extract.

\subsection{Enzymatic activity}

Cellular enzymatic activity was checked before and after heat treatment $\left(58^{\circ} \mathrm{C} / 5 \mathrm{~min}\right)$. For this purpose two enzymes were selected: $\beta$-galactosidase and superoxide dismutase (SOD). In both cases, cells were lysed as described above, and the soluble intracellular content was analyzed for enzymatic activity. $\beta$-galactosidase activity was determined by the ONPG ( $o$-Nitrophenyl- $\beta$-D-Galactopyranoside) hydrolysis method, by measuring the absorbance at $405 \mathrm{~nm}$ after $10 \mathrm{~min}$ of reaction time (Lederberg, 1950). SOD activity was measured using a kit based on the detection of WST-1(4-[3-(4-iodophenyl)-2-(4-nitrophenyl)-2H-5-tetrazolio]-1,3-benzene disulfonate sodium salt) which is reduced by superoxide anions. Reduced WST- 1 is measured by absorbance at $438 \mathrm{~nm}$ (ScienCell, Carlsbad, CA, USA).

\subsection{Statistical analysis}

The experimental determinations were performed at least in duplicate with independent microbial cultures. Data in figure correspond to the average and the mean standard deviation (error bars). Student's $t$ tests were carried out using the GraphPad PRISM 5 software (GraphPad Software, Inc., San Diego, CA, USA), and differences were considered significant for $p \leq 0.05$.

\section{Results and discussion}

\subsection{Influence of the addition of glutathione in the growth medium, treatment medium and recovery medium on $E$. coli survival}

Fig. 1 shows the inactivation attained in $E$ coli BW25113 after a heat treatment at $58^{\circ} \mathrm{C}$ for $5 \mathrm{~min}$, of cells cultured in TSBYE with (Fig. 1B) and without glutathione (Fig. 1A) added to the growth medium. Cells were treated in PBS with or without glutathione and recovered in TSAYE with or without glutathione added. As it can be observed in the graphs, external glutathione exerted a different effect, depending on the moment of the addition.

The presence of glutathione in the growth medium did not exert any influence $(p>0.05)$, and $E$. coli cells grown with and without glutathione, in TSBYE, showed the same pattern of heat resistance, independently of the treatment and recovery conditions used.

The presence of $10 \mathrm{mM}$ glutathione added in the heating medium protected $E$. coli against heat inactivation under all the experimental conditions used $(p<0.05)$. This protective effect was of notable magnitude, ranging between 1.6 and $2.0 \mathrm{log}$ cycles, under these particular treatment conditions $\left(58^{\circ} \mathrm{C} / 5 \mathrm{~min}\right)$. When glutathione was added in the recovery agar it also exerted a protective effect in heated $E$. coli cells. However this effect was of lower magnitude, accounting for 0.3-1.0 log cycle, and was statistically significant only in two cases.

Given the fact that the presence of glutathione in the growth medium did not modify the behavior of cells, cells were always grown in TSBYE without glutathione thereafter, for heat resistance experiments.

We studied $(n=2)$ if the protective role of glutathione against heat inactivation was a common effect on various microorganisms, using Salmonella enterica serovar Senftenberg $775 \mathrm{~W}$ and Lactobacillus plantarum CECT 748. Fig. 2A and B show that the inactivation was higher when cells were treated in PBS without glutathione in both cases. Thus, these results seem to confirm that the addition of glutathione in the heating medium protected cells of different prokaryote groups, Gram negative and Gram positive, against heat inactivation.

It has to be pointed out that the effect of glutathione in the heating medium was concentration-dependent, in such a way that protection increased with the externally added concentration up to a certain threshold, which was different depending on the microorganism studied. Once that threshold was surpassed, glutathione exerted a sensitization effect. For instance, concentrations up to $8 \mathrm{mM}$ progressively protected $L$. plantarum against heat, whereas $10 \mathrm{mM}$ already sensitized cells. For E. coli BW25113, higher concentrations, $20 \mathrm{mM}$, sensitized cells to heat (data not shown). The reasons behind this behavior are not known and deserve further attention.

\subsection{Relation between intracellular glutathione, soluble protein and enzymatic activity}

We measured the amount of intracellular glutathione in E. coli cells grown in TSBYE without glutathione and treated with or without glutathione (Table 1). The amount of intracellular soluble protein was also measured. Cells heated in the presence of $10 \mathrm{mM}$ glutathione showed a much higher intracellular content (nM glutathione/ml cellular extract) than untreated cells, almost 7 fold higher, and also than cell heated in PBS without glutathione, 16 fold higher. In fact, glutathione appeared to be slightly depleted from cells heated in PBS without external glutathione added. When we attempted to normalize the glutathione content in relation to the total soluble protein, in order to minimize the possible influence of the efficacy of the mechanical lysis method used, we realized that the intracellular soluble protein content was actually very low in heated cells, as compared to untreated cells, especially in cells heated in PBS without glutathione added. Cells heated in PBS with glutathione maintained $21 \%$ of the soluble protein content of native cells, whereas cells heated in PBS without glutathione retained only $3 \%$. In our opinion, this difference in protein content retention cannot be attributed to experimental variations in the efficacy of the lysis method. A plausible explanation is that intracellular protein would be denatured due to the exposure to heat, thus becoming insoluble. Therefore, according to these results, cells heated in the presence of glutathione would retain a significantly higher amount of soluble protein, fact that could contribute to their greater survival capability. This effect can be attributed to the capacity of glutathione to form mixed disulfides with unfolded proteins, thus preventing the irreversible oxidation of thiol groups in proteins and helping in recovery of their native state (Masip et al., 2006). 
A

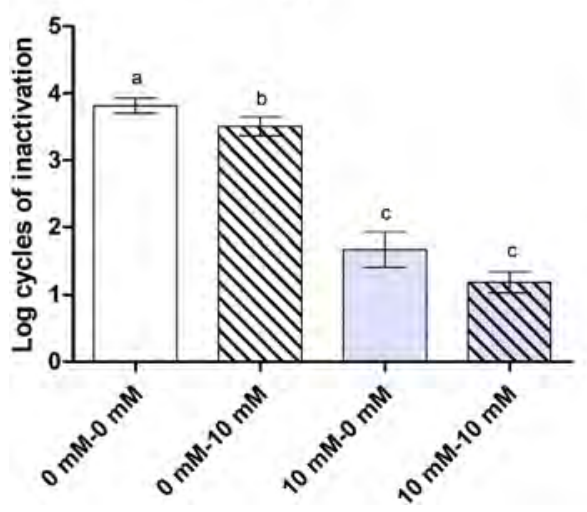

B

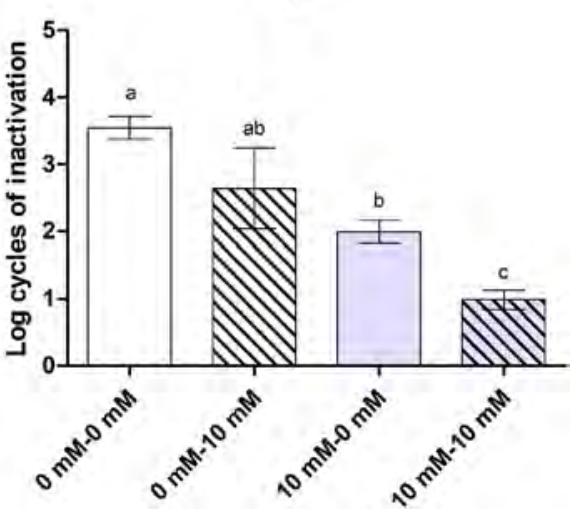

Fig. 1. $\log 10$ cycles of inactivation of $E$. coli BW25113 grown in TSBYE in the absence (A) or presence (B) of glutathione and treated at $58{ }^{\circ} \mathrm{C}$ for 5 min in PBS without (white bars; 0-0, 0-10) or with glutathione (grey bars; 10-0, 10-10). Cells were recovered in TSAYE without (plain bars; 0-0, 10-0) or with (stripped bars; 0-10; 10-10) glutathione added $(n=3)$. Different letters indicate statistical differences $(p<0.05)$.

In order to further investigate this aspect, we tested whether the activity of two different cellular enzymes, $\beta$-galactosidase and SOD, was preserved or not after heating in the presence of glutathione. The results are included in Table 2. It has to be noted that the $E$. coli strain used for the $\beta$-galactosidase activity was strain CECT 4201, due to the inability of strain BW25113 to produce this enzyme. Results obtained show that the presence of glutathione during heating preserved the activity of the two enzymes tested. The protection exerted by glutathione took place inside the cell. However, it has to be remarked that we also observed that isolated $\beta$-galactosidase enzyme was stabilized by glutathione in vitro against heat (data not shown). It is reasonable to think that the thermostabilization of proteins and particular enzymes may play a role in cell survival, and perhaps in ulterior cellular processes involved in recovery of damages inflicted by heat.

\subsection{Influence of the addition of glutathione in the treatment medium on $E$.} coli ROS content, membrane permeabilization and protein aggregation

In order to further explore the mechanisms of the protective effect of glutathione during heating, cells were heat treated $\left(58^{\circ} \mathrm{C} / 5 \mathrm{~min}\right)$ and the presence of ROS (DHE staining) and permanent permeabilization of the membrane (PI staining) after treatment were studied. Fig. 3 includes the percentage of cells with a positive staining for DHE and for PI after heating. The figure shows that a notable lower percentage of cells showed staining when they had been heated in the presence of glutathione. Therefore, in addition to the thermo-protective effect on proteins, the presence of glutathione in the heating medium was related to a reduction in the intracellular ROS levels present after heating, and also to a stabilization of the membranes against the action of heat.

With the aim of further study the protective role of glutathione against protein denaturation in situ, the formation of protein aggregates inside the cells was explored.

Fig. 4 shows the microphotographs of cells heated in PBS without glutathione (4A) and with glutathione (4B). The presence, size and location of protein aggregates can be clearly observed by fluorescein

A

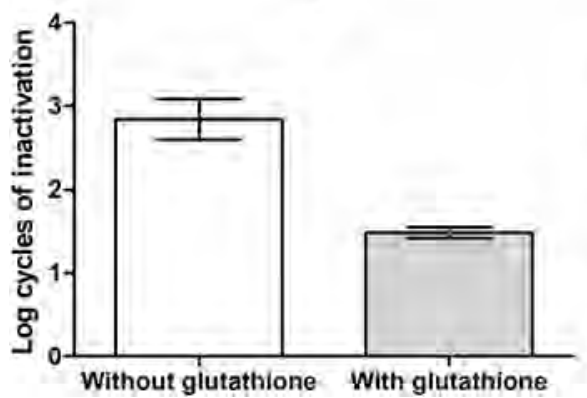

Table 1

Amount of intracellular glutathione $(\mathrm{nMol} / \mathrm{mL})$ and total soluble protein $(\mathrm{mg} /$ $\mathrm{mL}$ ) in $E$. coli cells grown in TSBYE without glutathione, treated with and without glutathione $\left(58^{\circ} \mathrm{C} / 5 \mathrm{~min}\right)$. Data in Table correspond to the average and the standard deviation ( $n=2$ biological and 3 technical replicates). Different letters in columns indicate statistical differences $(p<0.05)$.

\begin{tabular}{lll}
\hline & Glutathione $(\mathrm{nMol} / \mathrm{mL})$ & Protein $(\mathrm{mg} / \mathrm{mL})$ \\
\hline Untreated & $9.37 \pm 2.19^{\mathrm{a}}$ & $7.61 \pm 0.239^{\mathrm{a}}$ \\
Treated with glutathione & $63.2 \pm 2.89^{\mathrm{b}}$ & $2.27 \pm 0.00634^{\mathrm{b}}$ \\
Treated without glutathione & $3.85 \pm 1.22^{\mathrm{a}}$ & $0.327 \pm 0.0163^{\mathrm{c}}$ \\
\hline
\end{tabular}

Table 2

Concentration of $B$-gal (UA/mL) in $E$. coli CECT4201 and SOD (UA/mL) in $E$. coli BW25113, after heating in the absence and presence of glutathione $\left(58^{\circ} \mathrm{C}\right.$ / $5 \mathrm{~min})$. Data in Table correspond to the average and the standard deviation ( $n=2$ biological and 3 technical replicates). Different letters in columns indicate statistical differences $(p<0.05)$.

\begin{tabular}{lll}
\hline & $\beta$-Galactosidase $(\mathrm{UA} / \mathrm{mL})$ & SOD $(\mathrm{UA} / \mathrm{mL})$ \\
\hline Untreated & $542 \pm 23.2^{\mathrm{a}}$ & $5.26 \pm 0.236^{\mathrm{a}}$ \\
Treated with glutathione & $402 \pm 27.2^{\mathrm{b}}$ & $5.73 \pm 0.707^{\mathrm{a}}$ \\
Treated without glutathione & $5.79 \pm 2.68^{\mathrm{c}}$ & $2.58 \pm 0.462^{\mathrm{b}}$ \\
\hline
\end{tabular}

fluorescence, and even in phase contrast photographs. Cells treated without glutathione presented a higher amount of protein aggregates, which were of bigger size and more dispersed as compared to those in cells treated with glutathione. Govers and Aertsen (2015) proposed that the protein aggregate surface area exposed in the cytoplasmic milieu has cytotoxic effects, functionally interferes with essential cellular repair processes, and thus limits bacterial survival. These results are in accordance with those obtained with total soluble protein determinations, and with enzymatic activities (Tables 1 and 2), and confirm the protective effect of glutathione against protein destabilization by heat exposure.
B

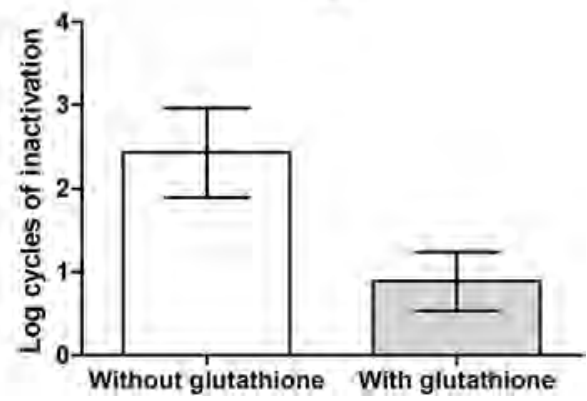

Fig. 2. Log10 cycles of inactivation of Salmonella senftenberg $775 \mathrm{~W}$ (A), recovered in TSAYE, and Lactobacillus plantarum 748 (B), recovered in MRS agar, treated at $58^{\circ} \mathrm{C}$ for 20 and 6 min, respectively, in PBS with (grey bars) and without glutathione (white bars). Concentration of glutathione was $10 \mathrm{mM}$ for Salmonella and $5 \mathrm{mM}$ for L. plantarum $(n=2)$. 


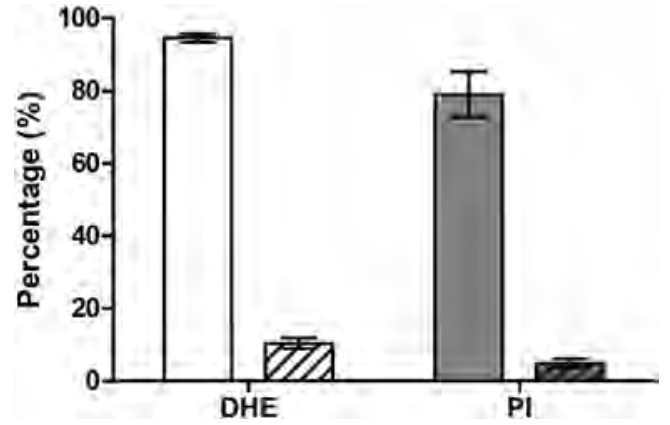

Fig. 3. Percentage of $E$. coli BW25113 cells stained with DHE (white bars) and PI (grey bars) after heating $\left(58^{\circ} \mathrm{C} / 5 \mathrm{~min}\right)$ in PBS with (stripped bars) and without glutathione (plain bars) added $(n=2)$.
Phase contrast

A

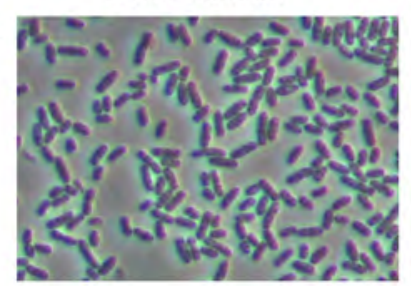

B

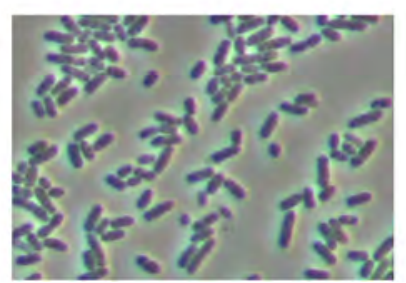

Fluorescence
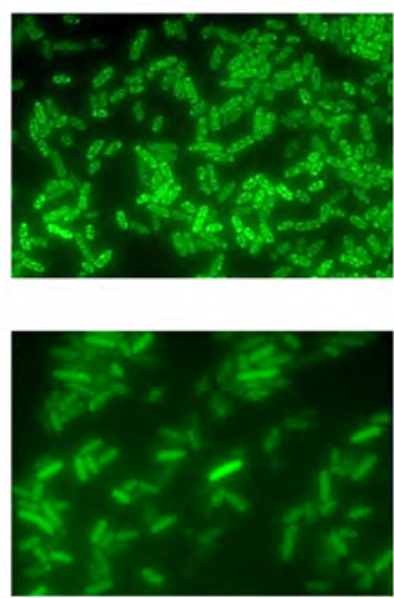

Fig. 4. Protein aggregates in E. coli BW25113 heat treated $\left(58^{\circ} \mathrm{C} / 10 \mathrm{~min}\right)$ in absence (A) or presence (B) of glutathione added.

\subsection{Sublethal injury and recovery after treatment}

The occurrence and repair of sublethally injured cells after treatment was studied through differential plate techniques, by the use of four different agars and two liquid media (Fig. 5). In this case, cells were subjected to a mild heat treatment $\left(58^{\circ} \mathrm{C} / 1 \mathrm{~min}\right)$, with the aim of obtaining sublethally injured cells, to study their recovery. Cells were treated in the absence (5A, 5C) and presence (5B) of glutathione. Once treated, cells were suspended in liquid media for recovery (TSBYE in 5A and $5 B$ and TSBYE $+10 \mathrm{mM}$ glutathione in $5 \mathrm{C}$ ). Samples were withdrawn from the liquid medium after 0, 30, 60 and $120 \mathrm{~min}$ for plate count in non selective and in selective agars. Untreated cells (UT) were also plated in the different agars as a control. This experimental approach allows studying the occurrence of cellular damages along time after treatment, assuming that cells unable to grow in TSAYE- $\mathrm{NaCl}$ and in TSAYE-BS correspond to sublethally injured viable cells with compromised cytoplasmic and outer membranes, respectively.

Plate counts immediately after heat treatment (time 0 in the graphs) showed that cells were partially inactivated and partially sublethally injured. The amount of inactivated and sublethally injured cells was higher for cell suspensions treated in the absence of glutathione (Fig. 5A vs 5B). When cells were recovered in TSAYE (standard recovery conditions) $1.6 \mathrm{log}$ cycles of inactivation were attained, plus 2 additional log cycles in TSAYE-NaCl and in TSAYE-BS. In Fig. 5A it can be observed that injured cells started promptly to regain tolerance to $\mathrm{NaCl}$, which was completely restored after $60 \mathrm{~min}$ incubation in TSBYE. This fact indicates that the functionality of the cytoplasmic membrane was quickly recovered. Restoration of tolerance to bile salts was slower, and $120 \mathrm{~min}$ were needed for full recovery of the selective permeability of the outer membrane.

The addition of glutathione to the heating medium (Fig. 5B) caused a decrease in the inactivation degree, as expected $(0.8$ Log cycles). It also caused a drop in the amount of sublethally injured cells, which accounted only for an extra $0.5 \log$ cycle. These results indicate that the presence of glutathione during heating caused a thermostabilization of the envelopes, and are in accordance with those obtained with PI staining (Fig. 3).

Besides, it is worth noting that higher numbers of viable cells were detected in MM-Cys in anaerobic conditions (minimal medium plus cysteine) than in TSAYE (nutritionally complex medium). This effect can be more clearly observed for cells treated in PBS without glutahione (Fig. 5A). Some authors have already reported that minimal media may improve cell recovery, and this effect has been attributed to the fact that no traces of hydrogen peroxide, and other oxidative species, are formed during autoclaving and storage, contrary to complex medium (Mackey \& Seymour, 1987). Besides, it is important to note that under these recovery conditions, the amount of surviving cells was very similar for cells heated in presence and in absence of glutathione. This result suggests that the protective effect of glutathione during heating could be related, at least to some degree, to cellular disorders that can be counteracted during the recovery period, if the environmental conditions are adequate. According to our results, membrane structural alterations would be included among these disorders, but other cellular alterations cannot be excluded.

Finally, comparison of Fig. 5A and C allows evaluating the influence
A

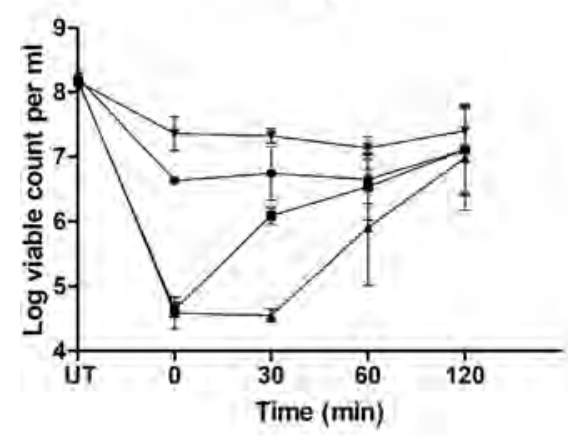

B

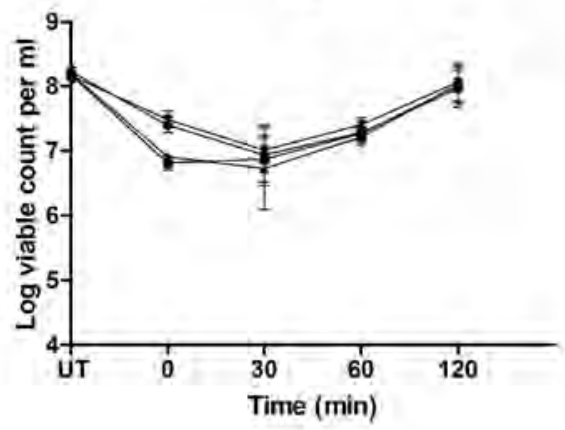

C

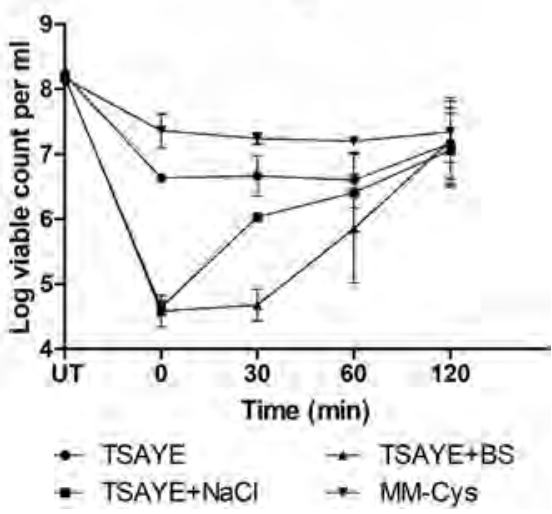

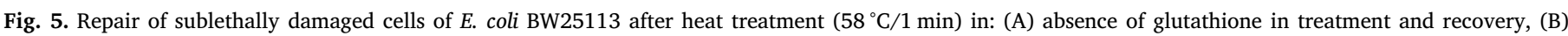

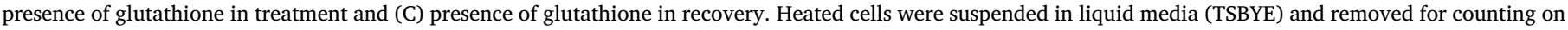
TSAYE ( $(\mathbf{)})$, TSAYE plus $4 \%$ sodium chloride $(\boldsymbol{\square})$, TSAYE plus $0.2 \%$ bile salts $(\boldsymbol{\Delta})$ and minimum media plus 3 mM cysteine $(\boldsymbol{\nabla})$. UT: untreated cells $(n=2)$. 
of the presence of glutathione in the liquid medium where cells were suspended for recovery. As it can be observed, recovery of the cytoplasmic and the outer membrane, i.e. impermeability of $\mathrm{NaCl}$ and bile salts, respectively, was very similar in liquid media with or without glutathione. This fact would indicate that the presence of external glutathione would not improve membranes repair processes, at least during the 2-h period here studied, and in the experimental conditions here tested.

Results presented in this investigation have shown that the presence of external glutathione protects bacterial cells against inactivation by heat exposure. This protection was observed on E. coli, S. enterica and $L$. plantarum, suggesting a general effect on cells of different types and physiology. We have demonstrated that in $E$. coli the presence of glutathione prevented damages and permeabilization in the membranes, caused a reduction in the intracellular level of ROS, and decreased the degree of protein aggregation inside the cytoplasm. In fact, glutathione caused a direct stabilization effect on enzymes against heat. All these cellular events could be involved in cell inactivation, and could be somehow interrelated. For instance, we can speculate that a damaged cytoplasmic membrane may be related to unbalances in the electron transport chain, thus giving rise to increased amounts of ROS level inside the cells (Imlay, 2015; Stephens, Druggan, \& Nebe-von Caron, 2000), which could be poorly controlled due to loss of activity of detoxifying enzymes, as we have demonstrated with SOD. Alternatively, a higher level of ROS and other toxic species, perhaps resulting from the loss of activity of protective enzymes, depletion of antioxidant molecules and/or other mechanisms, may be the actual cause of secondary injuries in membranes, proteins and other cellular structures. Glutathione seemed to exert a protective effect at various cellular levels.

These results add new knowledge about bacterial inactivation and survival by stressing agents, in this case, heat. Besides, bacterial cell and protein and enzyme protection against the action of heat by glutathione may also be of interest to pharmaceutical and starter industries.

\section{Acknowledgements}

The authors would like to thank the European Regional Development Fund, MINECO-CICYT (projects AGL2012-33522; AGL2015-69565-P) and the Department of Innovation Research and University of the Aragón Government and European Social Fund (FSE) for the support (predoctoral grant M. Marcén, C093/2014).

\section{References}

Aertsen, A., De Spiegeleer, P., Vanoirbeek, K., Lavilla, M., \& Michiels, C. W. (2005) Induction of oxidative stress by high hydrostatic pressure in Escherichia coli. Applied and Environmental Microbiology, 71, 2226-2231.

Cabiscol, E., Tamarit, J., \& Ros, J. (2000). Oxidative stress in bacteria and protein damage by reactive oxygen species. International Microbiology, 3, 3-8.

Cebrián, G., Condón, S., \& Mañas, P. (2017). Physiology of the inactivation of vegetative bacteria by thermal treatments: Mode of action, influence of environmental factors and inactivation kinetics. Food, 6, 107.

Fahey, R., Brown, W., Adams, W., \& Worsham, M. (1978). Occurrence of glutathione in bacteria. Journal of Bacteriology, 133, 1126-1129.

Fahey, R. C. (2013). Glutathione analogs in prokaryotes. Biochim Biophys Acta (BBA)General Subjects, 1830, 3182-3198.

Farr, S. B., Natvig, D. O., \& Kogoma, T. (1985). Toxicity and mutagenicity of plumbagin and the induction of a possible new DNA repair pathway in Escherichia coli. Journal of Bacteriology, 164, 1309-1316.

Gerhardt, P. (1994). Methods for general and molecular bacteriology. American Society for Microbiology.

Gomes, A., Fernandes, E., \& Lima, J. L. (2005). Fluorescence probes used for detection of reactive oxygen species. Journal of Biochemical and Biophysical Methods, 65, 45-80.

Govers, S. K., \& Aertsen, A. (2015). Impact of high hydrostatic pressure processing on individual cellular resuscitation times and protein aggregates in Escherichia coli. International Journal of Food Microbiology, 213, 17-23.

Hassan, H. M., \& Fridovich, I. (1979). Intracellular production of superoxide radical and of hydrogen peroxide by redox active compounds. Archives of Biochemistry and Biophysics, 196, 385-395.

Imlay, J. A. (2013). The molecular mechanisms and physiological consequences of oxidative stress: Lessons from a model bacterium. Nature Reviews. Microbiology, 11, 443.

Imlay, J. A. (2015). Diagnosing oxidative stress in bacteria: Not as easy as you might think. Current Opinion in Microbiology, 24, 124-131.

Lederberg, J. (1950). The beta-d-galactosidase of Escherichia coli, strain K-12. Journal of Bacteriology, 60, 381.

Mackey, B. (2000). Injured bacteria. In M. Lund, T. C. Baird-Parker, \& G. W. Gould (Eds.). The Microbiological Safety and Quality of Food Vol. I (pp. 315-341). Gaithersburg: Aspen Publisher.

Mackey, B. M., \& Seymour, D. A. (1987). The effect of catalase on recovery of heat-injured DNA-repair mutants of Escherichia coli. Microbiol, 133, 1601-1610.

Mañas, P., \& Mackey, B. M. (2004). Morphological and physiological changes induced by high hydrostatic pressure in exponential-and stationary-phase cells of Escherichia coli: Relationship with cell death. Applied and Environmental Microbiology, 70(3), 1545-1554.

Marcén, M., Ruiz, V., Serrano, M. J., Condón, S., \& Mañas, P. (2017). Oxidative stress in $E$. coli cells upon exposure to heat treatments. International Journal of Food Microbiology, 241, 198-205

Masip, L., Veeravalli, K., \& Georgiou, G. (2006). The many faces of glutathione in bacteria. Antioxidants \& Redox Signaling, 8, 753-762.

Mols, M., \& Abee, T. (2011). Primary and secondary oxidative stress in Bacillus. Environmental Microbiology, 13, 1387-1394.

Mols, M., Van Kranenburg, R., Van Melis, C. C., Moezelaar, R., \& Abee, T. (2010). Analysis of acid-stressed Bacillus cereus reveals a major oxidative response and inactivationassociated radical formation. Environmental Microbiology, 12, 873-885.

Nguyen, H. T., Corry, J. E., \& Miles, C. A. (2006). Heat resistance and mechanism of heat inactivation in thermophilic campylobacters. Applied and Environmental Microbiology, 72, 908-913.

Smelt, J., \& Brul, S. (2014). Thermal inactivation of microorganisms. Critical Reviews in Food Science and Nutrition, 54, 1371-1385.

Smirnova, G., \& Oktyabrsky, O. (2005). Glutathione in bacteria. The Biochemist, 70, 1199-1211.

Stanier, R. Y., \& Villanueva, J. R. (1996). Microbiología Reverté. Spain: Barcelona17-45. Stephens, P., Druggan, P., \& Nebe-von Caron, G. (2000). Stressed Salmonella are exposed to reactive oxygen species from two independent sources during recovery in conventional culture media. International Journal of Food Microbiology, 60, 269-285.

Suh, J. H., \& Knabel, S. J. (2000). Comparison of different reducing agents for enhanced detection of heat-injured Listeria monocytogenes. Journal of Food Protection, 63 1058-1063. 